\title{
Consequences of rigid and flexible learning
}

\author{
LINDA BAKER, JOHN L. SANTA, and JOHN M. GENTRY \\ Rutgers University, Douglass College, New Brunswick, New Jersey 08903
}

\begin{abstract}
Three experiments examined the consequences of learning material in rigid and flexible contexts. In Experiment 1, subjects studied and recalled a list of words in serial order. The subjects in one condition received the words in the same order for three trials, while subjects in the second condition received the words in a different random order on each trial. On the final trial, all subjects were required to study and recall the words in a new order. Although the rigid group showed better serial recall on the third trial, the flexible group was better on the final trial. Experiment 2 replicated these results with a new set of words. Experiment 3 used the same procedure but introduced a completely new set of words on the fourth trial. Similar results were again obtained. Taken together, these experiments suggest that studying material in a rigid context can restrict the flexibility of both learning and retrieval strategies.
\end{abstract}

Several experiments have demonstrated that conditions of encoding influence retrieval (Tulving \& Osler, 1968; Tulving \& Thomson, 1973). Subjects are often restricted at retrieval such that they can only access material via cues encoded at study. A recent series of experiments by Baker, Santa, and Lamwers (Note 1) has shown that the restrictiveness of the encoding context depends on the quality of the initial representation. When to-be-remembered words were embedded in wellintegrated encoding contexts, such as sentences or images, external retrieval cues were less effective than if the words had been studied in less integrated contexts. These results lead to the nonintuitive conclusion that good organization may only be beneficial to learning if people are allowed to recall in accordance with their own well-organized strategy.

The present series of experiments extends this notion to a serial recall paradigm which more closely approximates conditions of learning in natural situations. During study, students typically go over their notes time after time in the same sequence. Their serial recall of the material would eventually be close to perfect; but what happens if they must organize the information in a new way? The present experiments pursued this question by having subjects study a list of words in either a fixed or random order over a series of trials. On the final trial, subjects were asked to learn the material in a new order. We expected that subjects studying material in the fixed, well-integrated context would show better serial recall than the subjects studying the words in variable context. However, on the final trial, we expected the fixed-order subjects to exhibit a marked drop because they were forced to break away from their well-learned structure and learn the material in a new way. If the initial learning experience consists of variably ordered lists, there should be no decrement on

Carlton T. James sponsors this paper and takes full editorial responsibility for it. the final trial. The varied learning experience would have given subjects practice handling the material in a variety of ways. This flexibility should result in better final recall for the flexible condition than for the rigid condition.

\section{EXPERIMENT 1}

\section{Method}

Materials. The stimuli consisted of 15 concrete nouns, selected from the Paivio, Yuille, and Madigan (1969) norms. The words were arbitrarily arranged in a list and then three randomized versions were constructed for use on different trials. The words were assigned with the restrictions that no item appear in the same serial position on more than one list and that no two items appear in adjacent positions from list to list.

Design. The experiment consisted of a 2 (encoding condition) by 4 (trials) mixed factorial design. Subjects in the rigid condition studied and recalled the words in the same serial order over three trials. Subjects in the flexible encoding condition studied and recalled the words in a different order on each trial. On the fourth trial, all subjects studied and recalled the words in a new serial order. Subjects were 29 introductory psychology students who received course credit for their participation. There were 18 subjects in the rigid condition and 11 subjects in the flexible condition.

Procedure. The lists were auditorially presented on tape at a $3-\mathrm{sec}$ rate. Four trials were given, in which subjects listened to the list and were then allowed 2 min to recall the words in serial order. Subjects in the rigid condition heard the words in the same order for three trials, and in a new order on the fourth, while subjects in the flexible condition received the words in different orders on all four trials.

\section{Results and Discussion}

The data were scored in two ways, by absolute position and by adjacency. Under the first system, a response was scored as correct if it appeared in the exact position of the input list, independent of other words. The adjacency system scored as correct each pair of words appearing together in output which appeared adjacently in input, regardless of absolute position. Analyses of variance were performed using both measures. Since the pattern of results are quite comparable, only 
Table 1

Mean Number of Words Recalled in Correct Serial Position

\begin{tabular}{clrrrc}
\hline \multirow{2}{*}{$\begin{array}{c}\text { Exper- } \\
\text { iment }\end{array}$} & Encoding & Condition & 1 & \multicolumn{4}{c}{ Trials } \\
\cline { 3 - 6 } & \multicolumn{1}{c}{2} & \multicolumn{1}{c}{3} & \multicolumn{1}{c}{4} \\
\hline \multirow{2}{*}{1} & Rigid & 6.06 & 11.72 & 13.83 & 7.94 \\
& Flexible & 5.09 & 8.46 & 7.27 & 9.64 \\
2 & Rigid & 4.69 & 8.69 & 12.23 & 3.00 \\
& Flexible & 4.18 & 6.73 & 6.73 & 5.46 \\
\multirow{2}{*}{3} & Rigid & 4.57 & 9.57 & 12.33 & 7.38 \\
& Flexible & 5.38 & 7.52 & 7.76 & 8.76 \\
\hline
\end{tabular}

the position scores will be considered in this and subsequent experiments.

The analysis revealed reliable main effects of condition $[\mathrm{F}(1,27)=6.51, \mathrm{p}<.02]$ and trials $[\mathrm{F}(3,81)=$ $20.00, p<.001]$, and a reliable interaction of Encoding Condition by Trials $[\mathrm{F}(3,81)=12.16, \mathrm{p}<.001]$. The results are presented in the top portion of Table 1 , showing the mean number of words recalled in correct serial position for the two conditions over trials. Performance of the rigid encoding group steadily increased over trials, while the flexible group was at a lower level of performance for the three trials. On Trial 3, the rigid group was significantly better than the flexible group. When a new random order was introduced on Trial 4, the rigid group showed a sharp decrease in performance. The flexible group, however, actually showed a slight improvement as they became more adept at learning the material in new ways over trials. Furthermore, the recall of the flexible group was higher than that of the rigid group on the fourth trial. A subtest comparing the difference between the conditions on this trial did not reach conventional significance levels. However, the trend is clearly present, suggesting that wellorganized learning can actually lead to worse performance than a less organized encoding context. In other words, subjects studying material in the same manner over trials experience difficulty in relearning the material according to a different organization scheme. Rigid encoding seems to restrict the flexibility of later learning and/or retrieval strategies.

\section{EXPERIMENT 2}

Experiment 2 was essentially a replication of Experiment 1 . We hoped to obtain stronger support for the detrimental effects of rigid learning and to extend our findings to a new set of materials. In addition, we included an interference task to eliminate the influence of short-term memory.

\section{Method}

The structure of the lists was identical to that of Experiment 1 , except that a new set of concrete nouns was used. Subjects again received three study-test trials in either fixed or random order and were given a new order on the fourth trial. The only procedural change from the previous experiment was the introduction of a 30 -sec interference task after the presentation of the fourth list. Subjects were 24 introductory psychology students, participating for extra credit. There were 13 and 11 subjects in the rigid and fixed conditions, respectively.

\section{Results and Discussion}

Analysis of variance of position scores showed a reliable main effect of trials $[\mathrm{F}(3,66)=14.69, \mathrm{p}<.001]$ and a reliable Condition by Trials interaction $[\mathrm{F}(3,66)=$ $14.40, \mathrm{p}<.001]$. The main effect of condition was not reliable $[F(1,22)=2.57, \mathrm{p}>.10]$. As Table 1 shows, the pattern of results is similar to that of Experiment 1. The interaction prevents the main effect of condition from being reliable; rigid subjects are better on the third trial, but flexible subjects are better on the fourth. In support of our major hypothesis, a subtest of Trial 4 means achieved significance $[F(1,66)=4.61, p<.05]$. Thus, the relative disadvantage of rigid encoding obtained in the first experiment has been shown to be absolute in the present experiment.

Taken together, the two experiments demonstrate that well-integrated study conditions can sometimes be detrimental. However, the source of the disadvantage is not clear. Does rigid encoding limit the flexibility of later encoding strategies in general, or does it somehow lead to greater interference in learning specific items in a new way? A third experiment was designed to clarify this question. Subjects again studied a list of words in fixed or random order for three trials, but on the fourth trial, a completely new set of words was presented. If the experiment yields the same pattern of results, a general transfer effect would be implicated. In other words, it would suggest that general learning strategies have been restricted, rather than a more limited interference from specific associations. If, on the other hand, the rigid group does not show a large decrement and does not perform below the level of the flexible subjects, it could be concluded that the detrimental effects were specific to a particular set of materials.

\section{EXPERIMENT 3}

\section{Method}

The experiment was identical to Experiment 2 except that, on the fourth trial, a new set of comparable concrete nouns was presented. A total of $\mathbf{4 2}$ subjects served in the experiment, with 21 in each condition.

\section{Results and Discussion}

Analysis of variance on position scores revealed a reliable main effect of trials $[F(3,124)=41.59$, $\mathrm{p}<.001]$ and an interaction of Condition by Trials $[F(3,120)=17.38, p<.001]$. The main effect of condition was not reliable $[\mathrm{F}(1,40)=2.24, \mathrm{p}>.10]$. As the bottom section of Table 1 shows, the first three trials essentially replicated Experiment 2. Performance on the fourth trial was also similar to the previous experiments, although the rigid subjects' decline in performance is not as dramatic. The flexible subjects show a slight increase in recall. 
The results are intermediate to those predicted by either of the two explanations of the decrement. They therefore suggest a combination of general and specific transfer effects as responsible for the decrement. The rigid subjects did not show as great a decline in the present experiment, suggesting that interference in treating old material in new ways was at least partially responsible for the decline. However, the fact that the rigid subjects were somewhat below the flexible level and, further, that the flexible subjects did not show a decrement with the new material suggests a general component. In other words, if the subjects establish a rigid encoding strategy, they will have difficulty learning material that cannot be encompassed within that strategy. Although a flexible strategy may not be immediately advantageous, in the long run it seems to be superior.

\section{REFERENCE NOTE}

1. Baker, L., Santa, J. L., \& Lamwers, L. L. The better the representation, the harder it is to retrieve. Paper presented at the Eastern Psychological Association meetings, New York, April 1975.

\section{REFERENCES}

Paivio, A., Yuille, J. C., \& Madigan, S. A. Concreteness, imagery and meaningfulness values for 925 nouns. Journal of Experimental Psychology Monograph Supplement, 1969, 76, 1-25.

Tulving, E., \& Osler, S. Effectiveness of retrieval cues in memory for words. Journal of Experimental Psychology, $1968,77,593-601$.

Tulving, E., \& Thomson, D. M. Encoding specificity and retrieval processes in episodic memory. Psychological Review, 1973, 80, 352-373.

(Received for publication August 30, 1976.) 